\title{
Limited Occurrence of Tristeza in Yuzu and Possible Tristeza-free Cultivation in Northernmost Commercial Yuzu-producing Areas of Japan
}

\author{
Eiko NAGAOKA-NAKAZONO ${ }^{1}$, Nami UECHI ${ }^{2}$, Hiroshi KATOH ${ }^{3}$, \\ Takashi FUJIKAWA ${ }^{2}$, Shin-ichi MIYATA ${ }^{4}$, Tsutomu FURUKAWA (retired) ${ }^{5}$, \\ Tomonori ASAKAWA ${ }^{6}$, Makoto SASAKI ${ }^{6}$, Riho KUWAHARA ${ }^{7}$, \\ Ok-Kyung KIM ${ }^{7}$, Hirosuke SHINOHARA ${ }^{7}$ and Toru IWANAMI ${ }^{7 *}$
}

${ }^{1}$ Japan International Research Center for Agricultural Sciences, Tsukuba, Japan

${ }^{2}$ Institute of Fruit and Tea Science, National Agriculture and Food Research Organization, Tsukuba, Japan

${ }^{3}$ Takasaki University of Health and Welfare, Takasaki, Japan

${ }^{4}$ Central Region Agricultural Research Center, National Agriculture and Food Research Organization, Tsukuba, Japan

${ }^{5}$ Ofunato Agricultural Development and Extension Center, Ofunato, Japan

${ }^{6}$ Iwate Agricultural Research Center, Kitakami, Japan

${ }^{7}$ Faculty of Agriculture, Tokyo University of Agriculture, Atsugi, Japan

\begin{abstract}
Citrus tristeza virus (CTV) commonly infects yuzu (Citrus junos) in most parts of the citrus-growing areas in Japan. This study examined the occurrence of CTV in the northernmost commercial citrusproducing areas of Japan. Colonies of the brown citrus aphid (Toxoptera citricidus) were detected within the areas investigated. However, 23 of the 41 trees that were examined by RT-PCR and both or either subject to stem-pitting observation and immunostrip testing were free of CTV. Several CTVfree trees were apparently more than 60 years old. A field trial revealed that all eight uninoculated seedlings tested negative for CTV at 52 months after transplanting. These results suggest that CTVfree yuzu production is possible in the Rikuzen-Takata and Ofunato areas of Japan.
\end{abstract}

Discipline: Agricultural Environment

Additional key words: Citrus junos Sieb. ex Tanaka, Great East Japan Earthquake, Toxoptera citricidus

\section{Introduction}

Yuzu (Citrus junos Sieb. ex Tanaka) is a cold-hardy sour citrus species that can grow in northern areas (Kawase et al. 1983). The yuzu fruit is very popular due to its characteristic flavor and is widely used as a dressing in Japanese cuisine (Miyazawa et al. 2009). The northernmost commercial yuzu-producing areas in Japan overlap with the main apple-growing regions. Specifically, yuzu has been grown for many years in the Rikuzen-Takata and Ofunato areas in Iwate Prefecture (around $39^{\circ} \mathrm{N}$ and $142^{\circ} \mathrm{E}$ ) (Fig. 1), primarily for ornamental purposes and production of the fruit, which is mainly consumed by the families of local farmers. However, in response to the recent increase in the popularity of yuzu, farmers in the Rikuzen-Takata and Ofunato areas have considered increasing the commercial production of yuzu, with potential financial benefits for these yuzu-producing areas.

Yuzu is highly susceptible to citrus tristeza virus (CTV), which commonly infects citrus species (Moreno et al. 2008, Dawson et al. 2015, Harper \& Cowell 2016). Yuzu trees infected by CTV grow poorly and often produce relatively small fruits with blemished skin (Ieki 2003). Many yuzu trees in the southern yuzu-producing areas of Japan are affected by tristeza. In Japan, CTV is mainly transmitted by the brown citrus aphid (Toxoptera citricidus) commonly found in the southern yuzuproducing areas (Ieki 2003). The conditions in those areas make it difficult to control the citrus tristeza

*Corresponding author: ti207181@nodai.ac.jp

Received 19 November 2019; accepted 27 February 2020. 
disease. However, a preliminary study indicated that some yuzu seedlings in the Rikuzen-Takata and Ofunato areas are more than 50 years old and CTV-free. Thus, the cultivation of CTV-free yuzu may be possible in these northern areas. The purpose of this study was to test this hypothesis. Moreover, the Rikuzen-Takata and Ofunato areas were severely damaged by the Great East Japan Earthquake in 2011. Another objective of this study was to develop a disease-free yuzu cultivation system that may help the locals recover from the natural disaster.

\section{Materials and methods}

\section{Field survey of yuzu trees in the Rikuzen-Takata and Ofunato areas}

The distribution of yuzu trees more than 20 years old in the Rikuzen-Takata and Ofunato areas was first roughly estimated based on information collected by the Ofunato Agricultural Development and Extension Center, and then confirmed by visiting each site several times in 2014-2015. The height and origin (self-rooted or grafted on rootstock) of the trees were visually assessed, and the circumference was measured at approximately 20 $\mathrm{cm}-30 \mathrm{~cm}$ above ground level. Information regarding the history and age of the trees was obtained from the owners when available.

\section{Evaluation of stem-pitting symptoms}

After the field survey, scions were collected from 22 yuzu trees and used to evaluate stem-pitting symptoms, which are strongly indicative of CTV infection. Stem pitting was evaluated essentially as previously described (Garnsey et al. 2005). Specifically, rough lemon seedlings were side-grafted with the yuzu scions, and then cut back to induce new growth. After grafting, the yuzu scions on rough lemon rootstocks were grown in an air-conditioned greenhouse in a $25^{\circ} \mathrm{C}$ (day) : $20^{\circ} \mathrm{C}$ (night) cycle. Yuzu shoots were peeled after one year of growth and stem pitting was rated visually.

\section{RT-PCR and an immunostrip test for detecting CTV}

Leaves were collected from 41 trees, including the 22 trees evaluated regarding their stem-pitting symptoms, and used for detecting CTV based on a reverse transcription polymerase chain reaction (RT-PCR). Total RNA was extracted and purified from 0.05 -g leaf midribs with the TRIzol Reagent (Thermo Fisher Scientific, Waltham, MA, USA). RT-PCR was performed with the CTV52 (5'-CGAGGTATCATTCTTCGAGC-3') and CTV-32 (5'-CGCCATAACTCAAGTTGCG-3') primers (Kano et al. 1998), and the PrimeScript One Step RT-PCR Kit (version 2) (Takara, Shiga, Japan) as per the following PCR program: $50^{\circ} \mathrm{C}$ for $30 \mathrm{~min}$. and $94^{\circ} \mathrm{C}$ for $2 \mathrm{~min}$.; 25 cycles of $94^{\circ} \mathrm{C}$ for $0.5 \mathrm{~min} ., 55^{\circ} \mathrm{C}$ for $0.5 \mathrm{~min} ., 72^{\circ} \mathrm{C}$ for 1 min.; and $72^{\circ} \mathrm{C}$ for $7 \mathrm{~min}$. The RT-PCR assay was completed according to a slightly modified version of a published procedure (Kano et al. 1998). At later stage of this study, another RT-PCR protocol was also used occasionally, incorporating a newer primer set and RT-PCR condition.

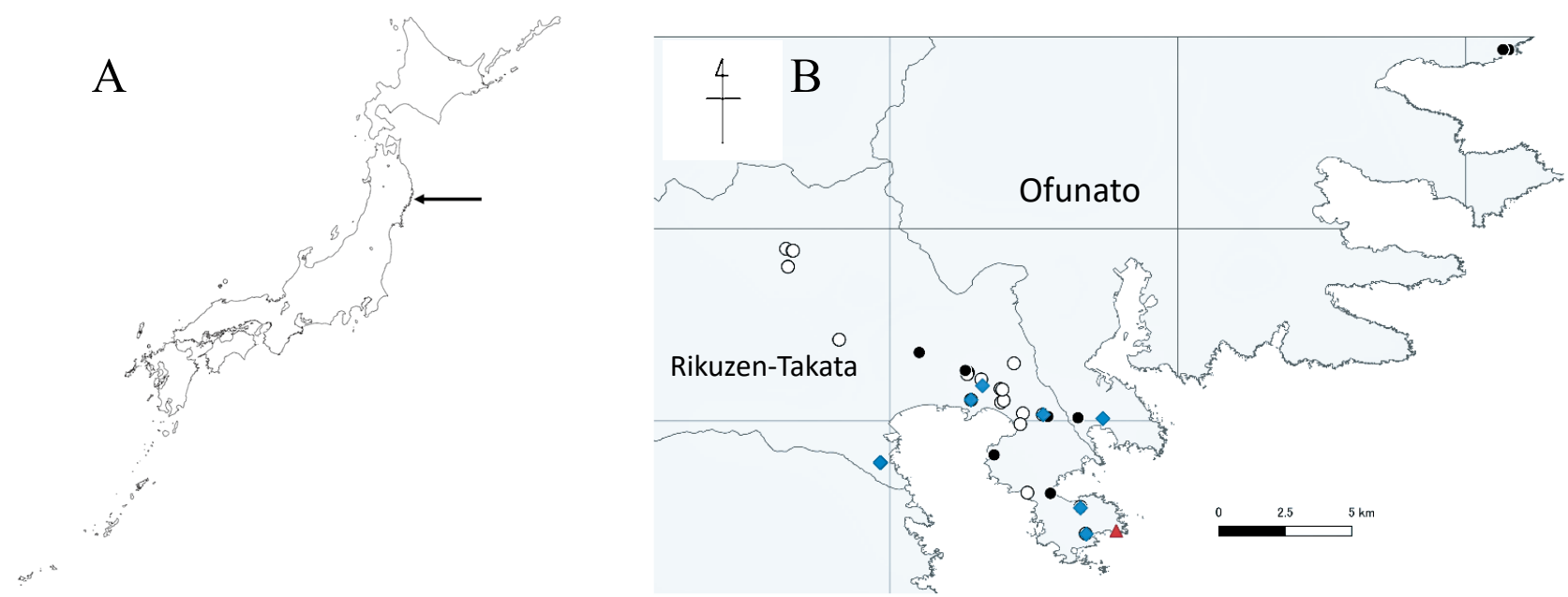

Fig. 1. Location (A) and schematic representation (B) of the distribution of yuzu trees in the Rikuzen-Takata and Ofunato areas

Fig. 1 A. The black arrow indicates the location shown in Fig. 1 B.

Fig. 1 B. White circles, black circles, and diamonds indicate CTV-free trees, CTV-infected trees, and trees with an undetermined disease status, respectively. A triangle indicates the location of the experimental field. Given the close proximity of some locations, some symbols overlap, resulting in fewer symbols than the number of trees listed in Table 1. A triangle indicates the location of the experimental field. The symbols were added to digital Japan tile map layers provided by the Geospatial Information Authority of Japan (https://www.gsi.go.jp/kiban/). 
Namely, RT-PCR was performed using a primer set (p25-F,5'ATGGACGACGARACAAAGAAATTGAAGA-3';p25-R,5'TCAACGTGTGTTRAATTTCCCAAGCT-3') (Roy et al. 2010). The first strand of cDNA synthesis was accomplished using $5.5 \mu \mathrm{l}$ of total RNA and the ReverTra Ace ${ }^{\circledR}-\alpha$ - kit (TOYOBO, Japan) as per the manufacturer's protocol. The tubes were then incubated at $42^{\circ} \mathrm{C}$ for 20 min., followed by inactivation of the reaction by heating at $99^{\circ} \mathrm{C}$ for $5 \mathrm{~min}$. in a thermal cycler. Takara Ex Taq ${ }^{\circledR}$ (Takara, Japan) was used for the PCR with amplification conditions (denature at $94^{\circ} \mathrm{C}$ for $5 \mathrm{~min}$.; followed by 30 cycles of $94^{\circ} \mathrm{C}$ for $0.5 \mathrm{~min}$., $57^{\circ} \mathrm{C}$ for $1.5 \mathrm{~min}$., and $72^{\circ} \mathrm{C}$ for $1.5 \mathrm{~min}$. with a final extension at $72^{\circ} \mathrm{C}$ for $10 \mathrm{~min}$.).

Young leaves were also collected from some yuzu trees for the detection of CTV with ImmunoStrip ${ }^{\circledR}$ (Agdia, Elkhart, IN, USA).

\section{Field surveys on the presence of the brown citrus aphid}

Field surveys were conducted in the summers of 2014 and 2015 to examine the presence of the brown citrus aphid, which is the most prominent CTV vector in Japan (Ieki 2003). Yuzu shoots were examined at several locations, and obvious candidate aphids (both winged and wingless) were collected and brought to the laboratory for definitive identification. The aphids were prepared as described by Sorin (2008) and identified based on the wing venation and the terminal abdomen. Additionally, insect bodies in ethanol were sent to Utsunomiya University and identified by Dr. K. Kagawa. Furthermore, total DNA was extracted from one aphid in each of the three colonies on the same tree, and the sequence of the barcode region (a partial mitochondrial COI gene, 567 bp) was amplified by PCR, sequenced, essentially as described by Foottit et al. (2008). After the sequence was determined, it was compared with those of $T$. citricidus from Australia (Accession No. EU701938), China (Accession No. JQ916183), India (Accession No. KJ702466), and two areas of the USA (i.e., Florida (Accession No. EU701937) and Guam (Accession No. EU701936)) in the DDBJ DNA database.

\section{Field trial of CTV-free cultivation}

Eight blocks were designed in a tandem arrangement at a field in Rikuzen-Takata, where various other promising yuzu lines had also been planted since 2014 (Figs. 2, 3). Each block contained an uninoculated CTVfree yuzu seedling and three yuzu seedlings that were graft-inoculated with one of the following CTV sources: M-23A (Ieki 2003), Y28-2, or K31. M-23A was separated using $T$. citricidus from the source $\mathrm{M}-23$ that was obtained from the source S-5 in navel orange after attenuation by

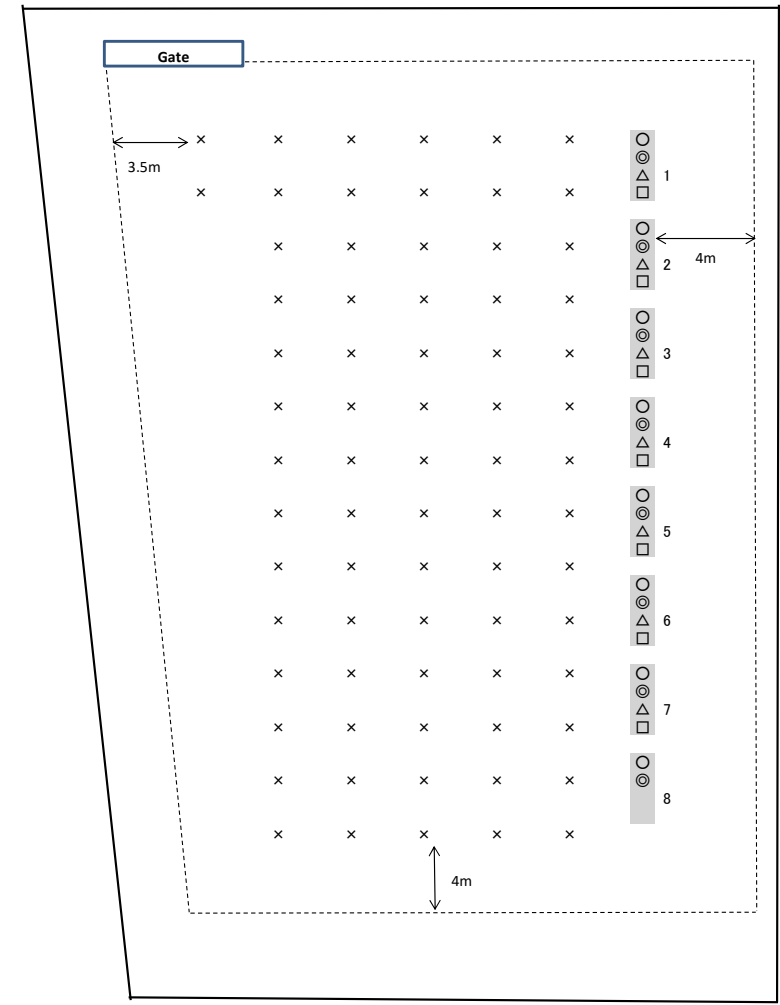

Fig. 2. Arrangement of the yuzu trees in the field trial Eight blocks are indicated by shaded boxes tagged with the block number. Single circles indicate uninoculated seedlings, whereas double circles, triangles, and squares indicate seedlings inoculated with CTV strains M-23A, Y28-2, and K31, respectively. Crosses indicate various other promising lines of yuzu and other sour citrus fruit species. Owing to an accident during transplanting, two seedlings are missing in block 8 .

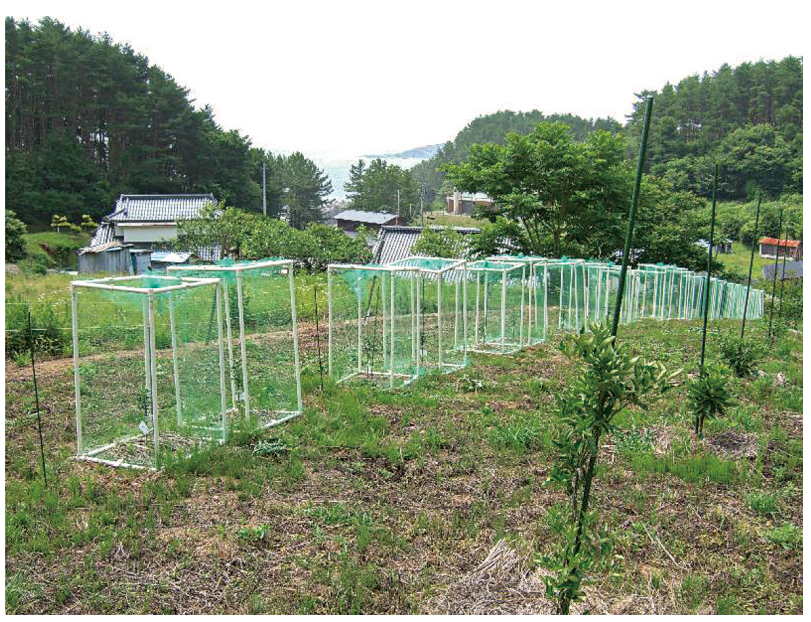

Fig. 3. Image of transplanted yuzu seedlings

Seedlings were photographed about two months after transplanting in the summer of 2015. Seedlings were covered with netted boxes to prevent the swallowtail butterfly from eating the young shoots during the first summer. The field experiment was continued until the summer of 2019. 
heat treatment. The sources Y28-2 and K31 were obtained from trees with ID numbers $28-2$ and 31 , respectively. These sources had been maintained in rough lemon seedlings grown in a greenhouse at the Institute of Fruit and Tea Science, National Agriculture and Food Research Organization in Tsukuba. All yuzu seedlings were first grown in a greenhouse at Tsukuba, Ibaraki for about two years, and then transplanted in the spring of 2015. After transplanting, the seedlings were covered with netted boxes to prevent eating damage by the swallowtail butterfly during the first summer (Fig. 3). The net was removed in the winter of 2015. The seedlings were then sprayed occasionally with a pesticide (acetamiprid) for protection against the swallowtail butterfly. Fungicides were not applied. To detect CTV, the shoots were examined in August for the presence of aphids, after which five leaves were collected from each tree for an RT-PCR test with CTV-specific primers. The detection of CTV was conducted yearly until the summer of 2019, with occasional modifications made on the number of samples.

\section{Results}

\section{Field survey of yuzu trees in the Rikuzen-Takata and Ofunato areas}

The field survey detected 145 yuzu trees in about 30 village sections in Rikuzen-Takata and Ofunato (Table 1). The survey was completed under the guidance of an expert who was very familiar with the local area to ensure that most of the yuzu trees more than 20 years old were identified. Of the 145 detected yuzu trees, the origin (self-rooted or grafted), age, and size were estimated for 71 trees. Most of the yuzu trees were grown in home gardens for ornamental purposes and household fruit consumption. A visual assessment indicated that 56 trees were self-rooted seedlings, whereas 15 trees were grafted on trifoliate rootstocks. The origins of some trees [with identification (ID) numbers 32-2, 49-1, and 49-2] were difficult to assess due to an inability to clearly analyze the trunks. Self-rooted trees were very likely seedlings because self-rooted yuzu trees are rarely produced by other means (e.g., marcotting, cutting). Some seedlings were more than 50 years old. And the trees with ID numbers $36-1,46-2$, and 47 were estimated to be more than 100 years old (Table 1 ).

\section{Biological indexing for stem-pitting symptoms}

For the biological indexing of CTV, scions were collected from 14 seedlings (ID numbers 113, 114, 116-1, $118,28-1,31,36-2,40,41,45-1,45-2,46-1,46-2$, and 47) and eight grafted trees (ID numbers $8,28-2,32-1,42,43-$
1, 43-2, 43-3, and 44) in the Rikuzen-Takata and Ofunato areas (Fig. 4). The scions were grafted onto rough lemon rootstocks to evaluate stem-pitting symptoms. Peeling the bark of the shoots extending from these scions revealed that only 4 of 14 seedlings (ID numbers $28-1,31$, 40, and 41) exhibited clear stem-pitting symptoms (Table 1). Conversely, three grafted trees (ID numbers 42 and 43-1, 43-3) lacked stem-pitting symptoms (Table 1). The tree 43-3 tested positive in RT-PCR (see below), and the lack of stem-pitting may be attributed to infection of mild strains of CTV. The reasons for no stem-pitting on trees 42 and 43-1 are unclear. One possible explanation is that these trees might have been grafted with scions taken from seedlings. Preliminary test results indicated that most of the yuzu seedlings in these areas were free of CTV.

\section{RT-PCR and immunostrip test for CTV}

Table 1 summarizes the RT-PCR and immunostrip test results for the detection of CTV as well as the final decisions on the CTV-free status of the analyzed yuzu trees. Four trees tested negative for CTV in all three analyses (i.e., biological indexing, RT-PCR, immunostrip test). Another 19 trees tested negative in two of the three analyses. These 23 trees were very likely free of CTV. It is noteworthy that some of the trees (ID numbers 118, 45-2, 46-1, 46-2, and 47) were more than 60 years old and had remained CTV-free. The RT-PCR and immunostrip results were inconsistent for the trees with ID numbers 7-1, 7-2, 20, 21-1, 28-1, 32-2, 33-2, 36-1, which resulted in an unclear disease status for some trees. Considered together, the RT-PCR and immunostrip test results as well as the partial biological indexing of 41 trees strongly indicated that at least 23 yuzu seedlings had been growing in the analyzed areas for more than 60 years, but were free of CTV (Table 1, Fig. 1).

\section{Field survey on the presence of the brown citrus aphid}

Apparent brown citrus aphid colonies were detected in one yuzu tree in Sakuzawa, Massaki, Ofunato during the summer of 2014. The tree was one of 28 trees growing in a small orchard located near the trees with ID numbers 43-1, 43-2, and 43-3 (Table 1). A few apparent brown citrus aphids were also detected on several other trees in the same orchard. On the basis of morphological characteristics, the aphids were identified as $T$. citricidus (Fig. 5). Moreover, a comparison of the 567-bp-long sequence of the barcode region (a partial mitochondrial COI gene) showed that the three aphids were identical in sequence and showed 99.8\% identity (566 bp /567 bp) with those of T. citricidus from Australia, China, India, 
Tristeza-free Cultivation of Yuzu in Northern Japan

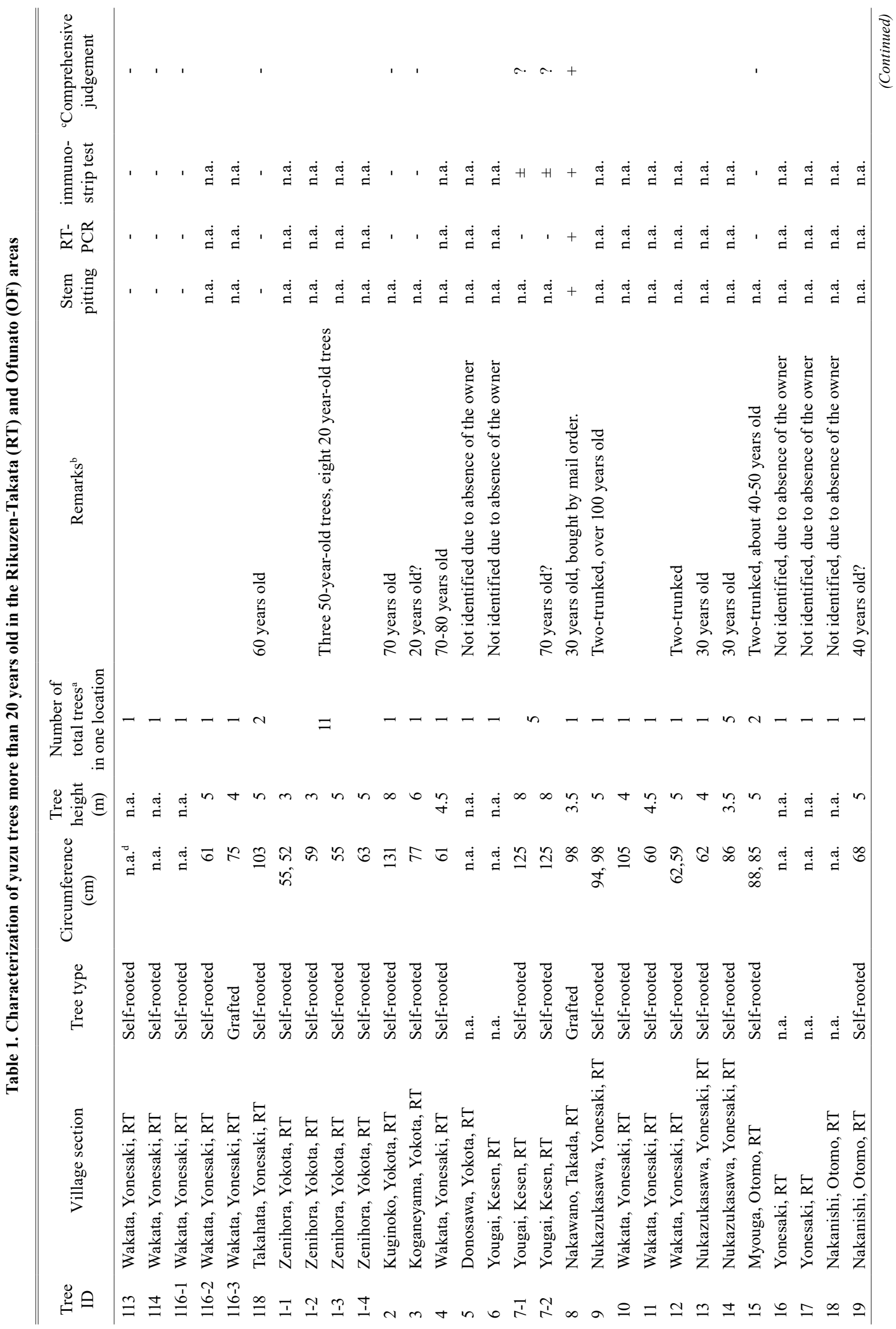


E. Nagaoka-Nakazono et al.

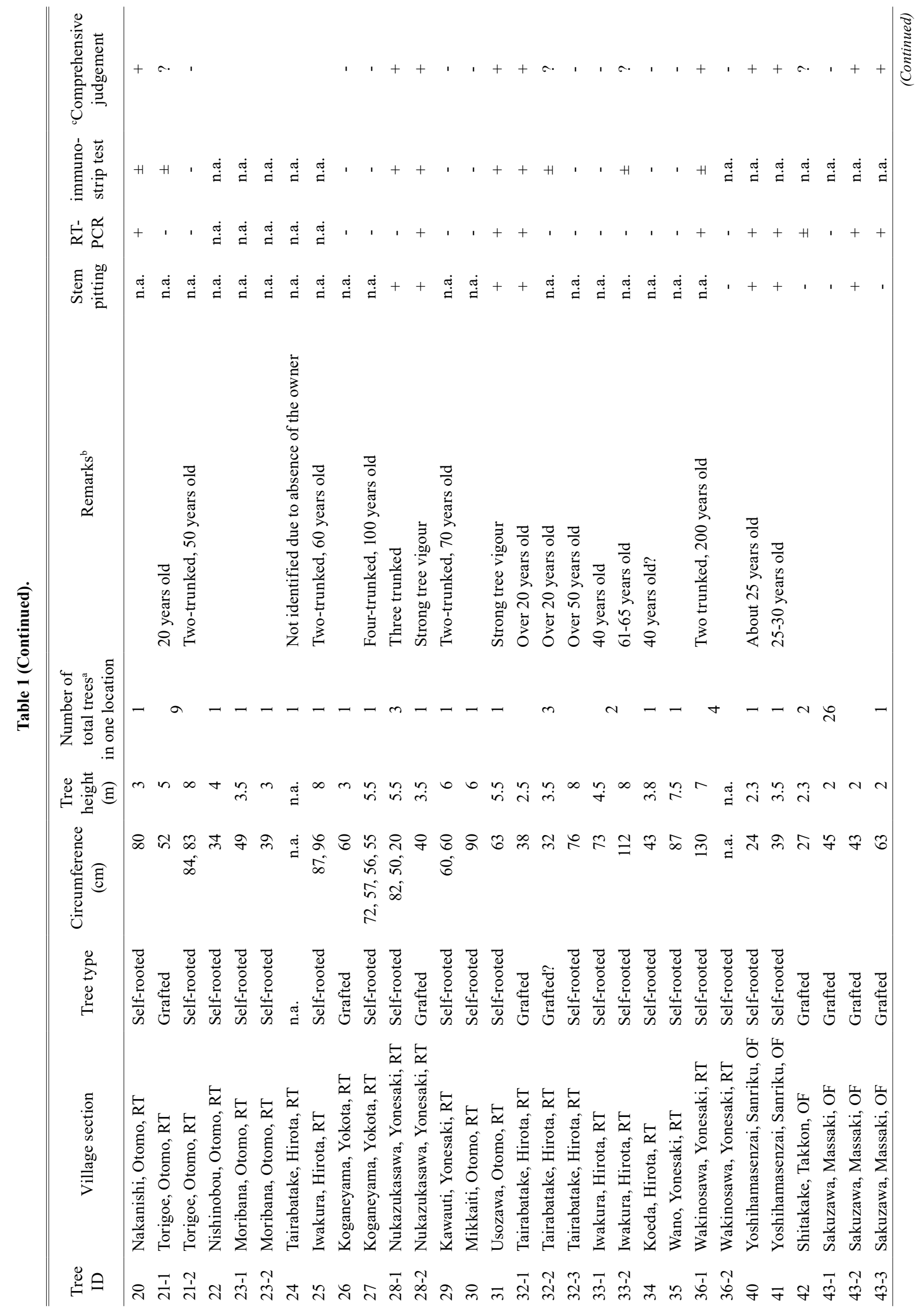


Tristeza-free Cultivation of Yuzu in Northern Japan

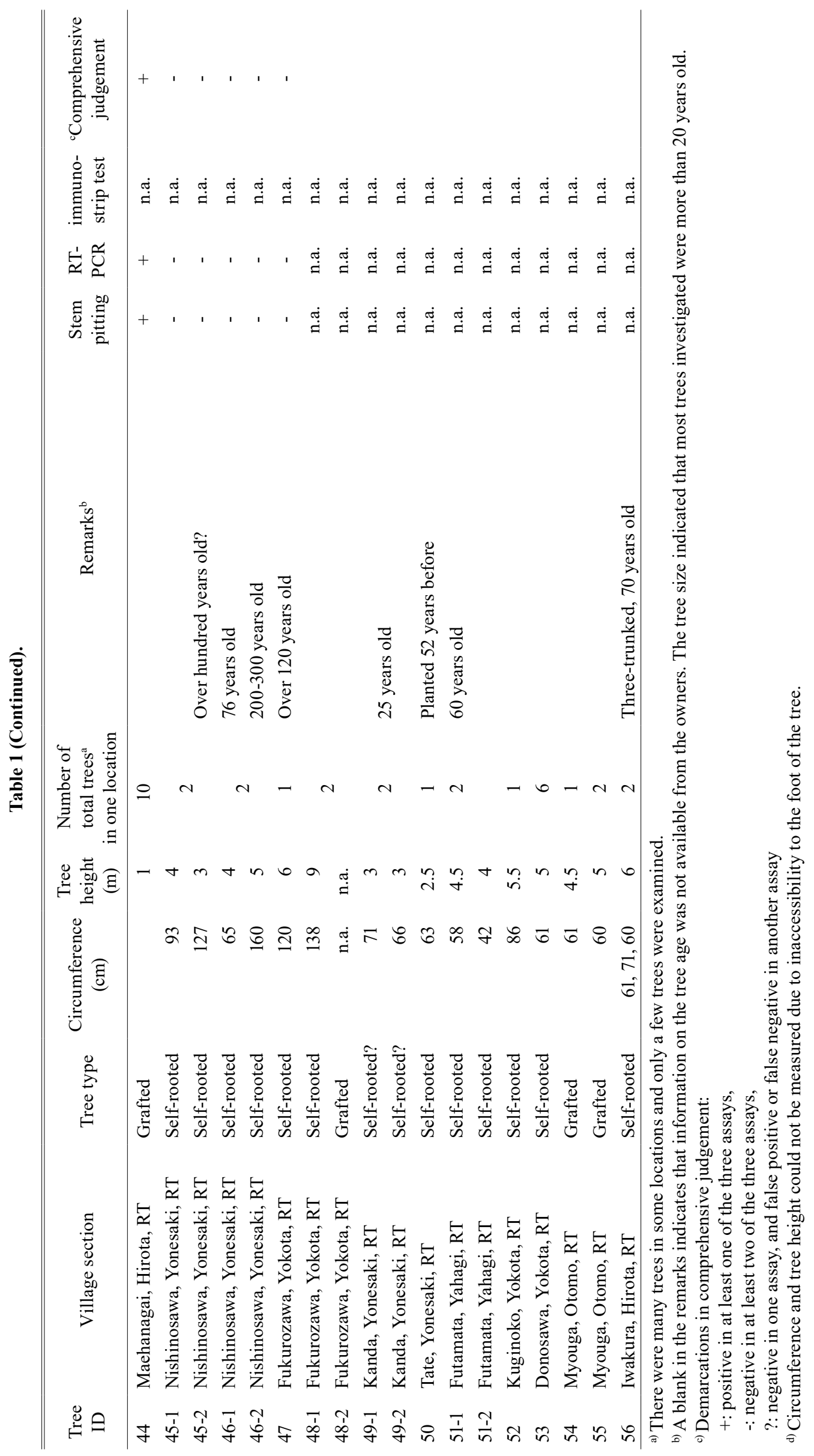




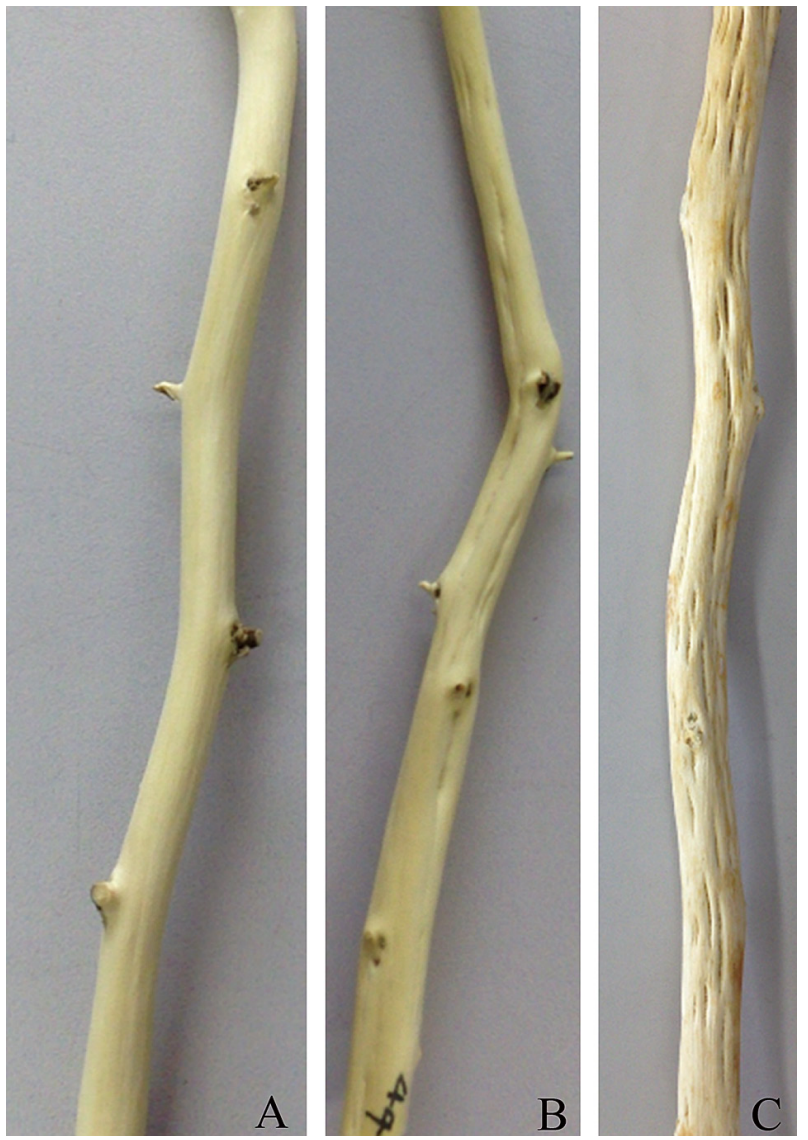

Fig. 4. Examples of stem pitting on shoots of yuzu

No stem pitting, typical stem pitting, and very severe pitting on the shoots of tree 43-3 (A), tree 44 (B), and a yuzu tree infected with severe strain of CTV-1595 (C), respectively.
Florida, and Guam, whereas the sequences of $T$. citricidus from foreign countries were identical. This result indicated a close relationship between T. citricidus in Ofunato and those from foreign countries.

To the best of our knowledge, this is the first time the brown citrus aphid has been detected in Iwate, and represents the northernmost occurrence of this aphid in Japan. A subsequent survey was conducted in September 2014 involving the trees with ID numbers 116, 29, 35, 361 , and 36-2, as well as trees in a commercial field near the tree with ID number116 and trees of various promising yuzu lines planted in the experimental field that was also used for the tristeza-free cultivation trial from 2015. Brown citrus aphids were not detected at these locations. However, another typical brown citrus aphid colony was detected in the summer of 2015 at a different location in Rikuzen-Takata.

\section{Field trial of tristeza-free cultivation}

All seedlings in the eight blocks grew vigorously during the field trial. All eight uninoculated seedlings tested negative for CTV, whereas all inoculated seedlings clearly tested positive, at 40 months (data not shown) and at 52 months after transplanting (Fig. 6). These results indicated that CTV was not transmitted from neighboring CTV-positive trees or other CTV-positive trees in the same field for more than four years. The brown citrus aphid was not detected in the field during the summer trials.
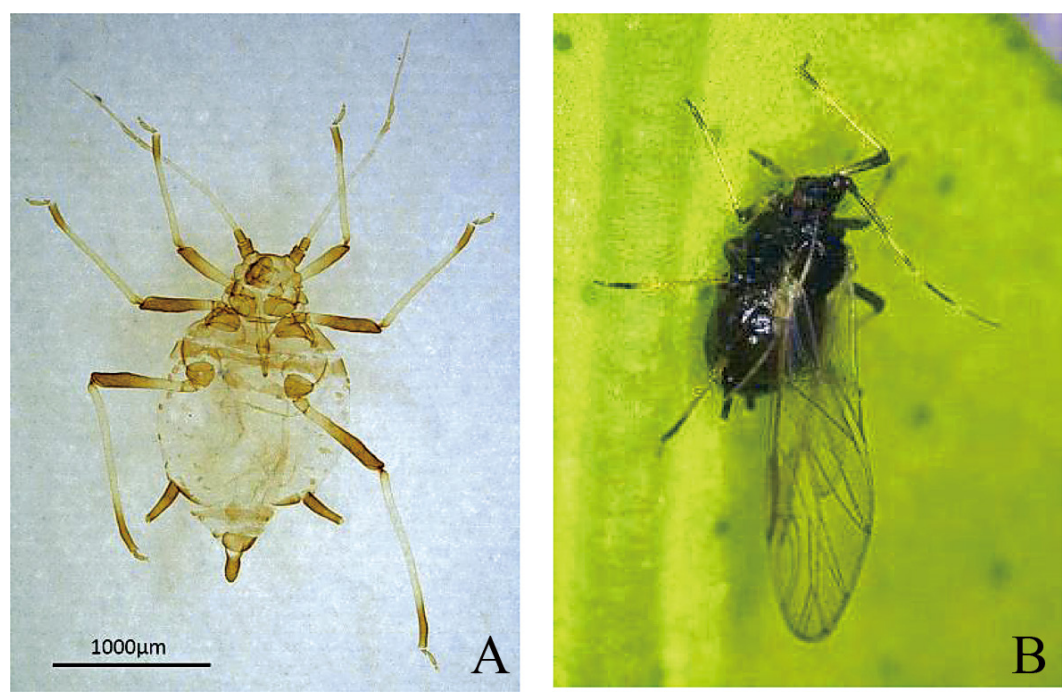

Fig. 5. Microscopic image of a brown citrus aphid collected from a yuzu tree in Ofunato

Optical image of a prepared brown citrus aphid (A) and a stereo microscopic image of a brown citrus aphid (B). The prepared aphid was from a colony on a yuzu tree in Sakuzawa, Massaki, Ofunato. 


\section{Discussion}

This study revealed that many yuzu trees growing in the Rikuzen-Takata and Ofunato areas for more than 50 years remain free of CTV. In addition, brown citrus aphids were detected at only a few locations. The reasons for the CTV-free status in the Rikuzen-Takata and Ofunato areas include the use of CTV-free materials (i.e., seedlings) and the sporadic occurrence of the vector insects. Most of the yuzu trees in the Rikuzen-Takata and
Ofunato areas will likely remain CTV-free for the foreseeable future if the current conditions are maintained.

Our field survey identified many CTV-free old yuzu seedlings in the Rikuzen-Takata and Ofunato areas. Regarding the presence of the vector insect, the brown citrus aphid is relatively rare in cold areas, and was only detected in the shoots analyzed in the summer. The winged adults of the brown citrus aphid disperse after making colonies, and thus only travel a short distance

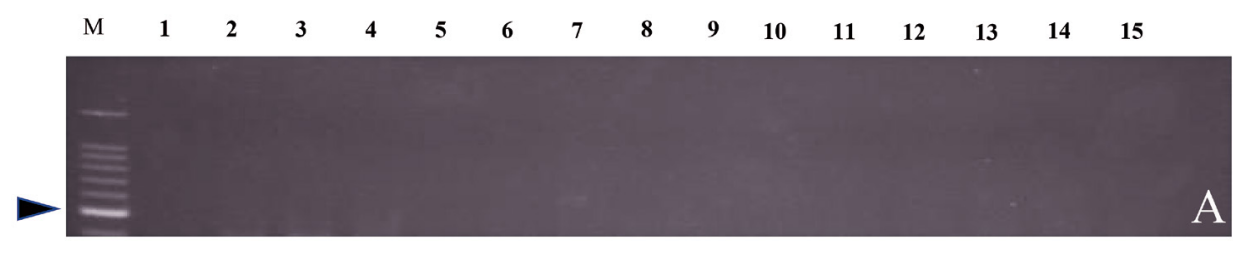

$\begin{array}{lllllllllllllllll}1 & 2 & 3 & 4 & 5 & 6 & 7 & 8 & 9 & 10 & 11 & 12 & 13 & 14 & 15 & M\end{array}$
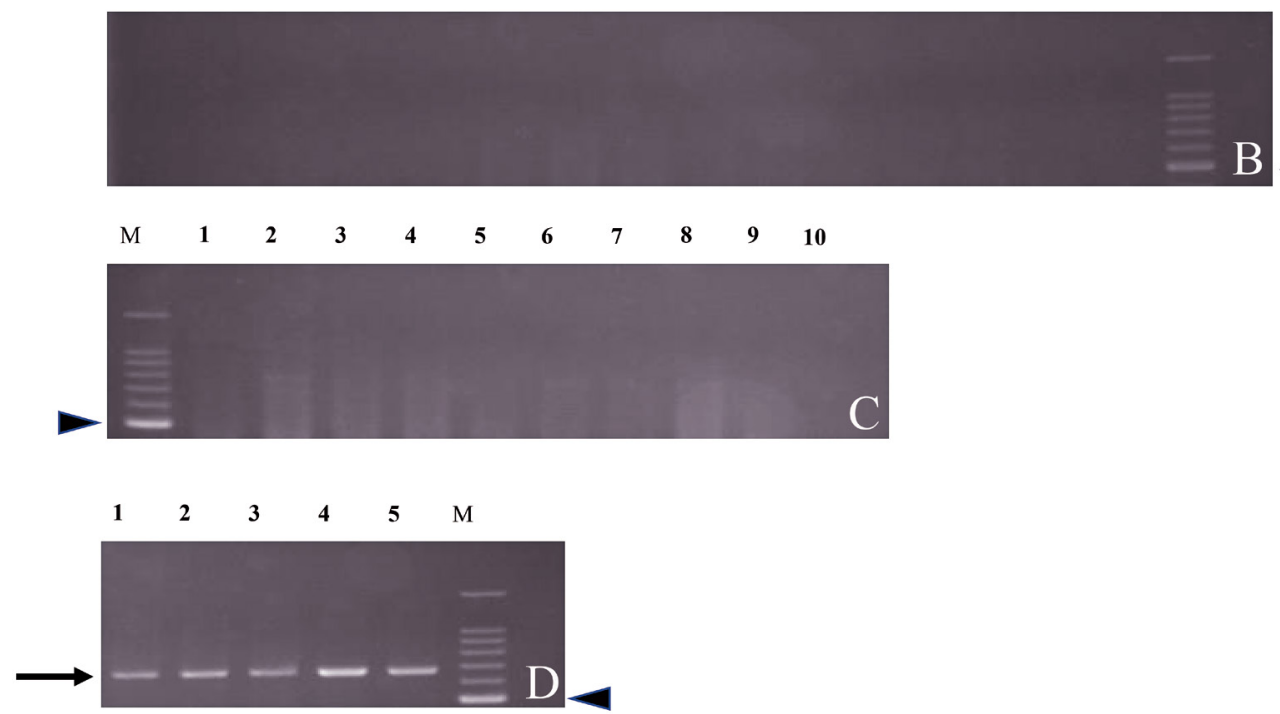

Fig. 6. Agarose gel electrophoresis of the RT-PCR products generated with CTV-specific primers and RNA isolated from seedlings growing in the experimental field

Five leaves collected from each tree were separately tested for CTV infection by RT-PCR using a primer set of $\mathrm{p} 25-\mathrm{F}$ and $\mathrm{p} 25-\mathrm{R}$ (see the Materials and methods section in the text). All leaves from the eight uninoculated seedlings tested negative.

A. Lanes 1 to 5: five leaves from an uninoculated seedling in block 1 (see Fig. 2); lanes 6 to10: five leaves from an uninoculated seedling in block 2; lanes 11 to 15: five leaves from an uninoculated seedling in block 3; M: 100-bp ladder marker (TaKaRa 100bp DNA Ladder, Takara Bio, Shiga, Japan) with the 500 -bp band indicated by a black triangle.

B. Lanes 1 to 5: five leaves from an uninoculated seedling in block 4; lanes 6 to10: five leaves from an uninoculated seedling in block 5; lanes 11 to 15: five leaves from an uninoculated seedling in block 6; M: 100-bp ladder marker (TaKaRa 100bp DNA Ladder, Takara Bio, Shiga, Japan) with the 500-bp band indicated by a black triangle.

C. Lanes 1 to 5: five leaves from an uninoculated seedling in block 7; lanes 6 to 10: five leaves from an uninoculated seedling in block 8; M: 100-bp ladder marker (TaKaRa 100bp DNA Ladder, Takara Bio, Shiga, Japan) with the 500-bp band indicated by a black triangle.

D. lanes 1 to 5: five leaves from a tree purchased from a CTV-infested area and grown in the same experimental field (with a tree arbitrarily chosen as a positive control from the trees indicated by crosses in Figure 2); M: 100-bp ladder marker (TaKaRa 100bp DNA Ladder, Takara Bio, Shiga, Japan) with the 500-bp band indicated by a black triangle. An arrow indicates the expected product size (672 bp). 
from their original host trees (Gottwald et al. 1996). It may be possible to contain the brown citrus aphid in the Rikuzen-Takata and Ofunato areas with regular spray applications of appropriate pesticides around places where it is detected. Consequently, it is feasible that some fields in the Rikuzen-Takata and Ofunato areas can be maintained free of CTV. Furthermore, the field trial results suggest that CTV-free yuzu cultivation is indeed possible in northern Japan.

The best option for yuzu cultivation in the RikuzenTakata and Ofunato areas might involve the use of CTVfree budwoods and regular chemical treatments during the summer. As shown in this study, there are many CTV-free old trees in the Rikuzen-Takata and Ofunato areas. CTV-free scions would be available from these old trees with the approval of the owners. A more rigorous chemical treatment may be necessary in a few areas where the brown citrus aphid is detected. This practice is strongly recommended in the cultivation manual distributed to local growers. If the locals faithfully execute this practice, the first and only CTV-free yuzuproducing areas in the world may be realized, thereby increasing the marketability of the resulting yuzu fruits. However, some local growers are interested in introducing popular yuzu lines from the southern yuzu-producing areas that are heavily infested with CTV. Doing so will likely contaminate the northern areas with CTV, and so it may be best to avoid bringing in new yuzu lines. The second-best option for yuzu cultivation, and the most practical choice, involves the introduction of budwoods and nursery trees with minimal stem pitting, which will decrease the risk of introducing highly virulent CTV strains. In Japan, the aphid population may increase considerably in new citrus shoots from summer to autumn (Korenaga et al. 2001). Therefore, if growers regularly apply insecticides during the summer, the risk of disseminating CTV will be further reduced.

In conclusion, this study revealed that CTV-free yuzu production is possible in the Rikuzen-Takata and Ofunato areas. Moreover, the production of CTV-free yuzu may result in fruit with relatively few blemishes, which is ideal for commercial yuzu production, and may help the Rikuzen-Takata and Ofunato areas to continue to recover from the effects of the Great East Japan Earthquake.

\section{Acknowledgments}

This study was supported by the project titled "A
Scheme to Revitalize Agriculture and Fisheries in Disaster Areas through Deploying Highly Advanced Technology" conducted by Japan's Ministry of Agriculture, Forestry and Fisheries. The authors wish to thank S. Obara and J. Oikawa for their assistance in conducting the field test. The authors also wish to thank Dr. S. Komazaki and Dr. K. Kagawa for their assistance in identifying the brown citrus aphid. Finally, we want to thank Edanz Group (www.edanzediting.com/ac) for editing a draft of this manuscript.

\section{References}

Dawson, W. O. et al. (2015) Citrus tristeza virus: Making an ally from an enemy. Ann. Rev. Phytopathol., 53, 137-155.

Foottit, R. G. et al. (2008) Species identification of aphids (Insecta: Hemiptera: Aphididae) through DNA barcodes. Mol. Ecol. Resour., 8, 1189-1201.

Garnsey, S. M. et al. (2005) Biological characterization of an international collection of citrus tristeza virus (CTV) isolates. In Proc. 16th Conf. IOCV, IOCV, Riverside, 75-93.

Gottwald, T. et al. (1996) Differential effects of Toxoptera citricida vs. Aphis gossypii on temporal increase and spatial patterns of spread of citrus tristeza. In Proc. 13th Conf. IOCV, IOCV, Riverside, 120-129.

Harper, S. J. \& Cowell, S. J. (2016) The past and present status of Citrus tristeza virus in Florida. J. Cit. Pathol., iocv_ journalcitruspathology_32387.

Ieki, H. (2003) The current situations and subject matters on research works of Citrus tristeza virus in Japan. Bull. Natl. Inst. Fruit Tree Sci., 2, 1-7. [In Japanese].

Kano, T. et al. (1998) Comparative sequence analysis of biologically distinct isolates of citrus tristeza virus in Japan. Ann. Phytopathol. Soc. Jpn., 64, 270-275.

Kawase, K. et al. (1983) Studies on the frost hardiness of citrus trees. Bull. Fruit Tree Res. Stn. D., 4, 25-46.

Korenaga, R. et al. (2001) Green citrus aphid, cotton aphid and brown citrus aphid. In A handbook of diseases and insect pests of fruit trees Vol.1 citrus, loquat and kiwifruit (revised version), Japan Plant Protection Association, Tokyo, Japan, p. 32 [In Japanese].

Miyazawa, N. et al. (2009) Novel character impact compounds in yuzu (Citrus junos Sieb. ex Tanaka) peel oil. J. Agric. Food Chem., 57, 1990-1996.

Moreno, P. et al. (2008) Citrus tristeza virus: a pathogen that changed the course of the citrus industry. Mol. Plant Pathol., 9, 251-268.

Roy, A. et al. (2010) Development and application of a multiplex reverse-transcription polymerase chain reaction assay for screening a global collection of Citrus tristeza virus isolates. Phytopathology, 100, 1077-1088.

Sorin, M. (2008) How to distinguish aphids. In Aphids of the fruit-trees, Plant protection special issue No. 11, Japan Plant Protection Association, Tokyo, Japan, pp. 21-37 [In Japanese]. 